\title{
Individual behaviour of Baltic cod Gadus morhua in relation to sex and reproductive state
}

\author{
B. Nielsen, K. Hüssy*, S. Neuenfeldt, J. Tomkiewicz, J. W. Behrens, K. H. Andersen
}

National Institute of Aquatic Resources, Technical University of Denmark, 2920 Charlottenlund, Denmark

\begin{abstract}
Information from data storage tags (DSTs) is conventionally used to infer movement patterns or reveal characteristics (e.g. temperature or salinity) of the environment surrounding tagged fish. Here we link data derived from DSTs with the reproductive state of tagged fish. Individual vertical activity of adult male and female Atlantic cod Gadus morhua L. in the Bornholm Basin was derived from DST measures and related to the individual histologically determined reproductive phase. Spawning migrations were identified by movements towards deeper and more saline waters. No difference was observed between sexes in the timing of the onset of migration and the duration of migration from feeding grounds to the spawning area. While there was no significant difference in duration of the spawning period between females and males, the histological characteristics suggest that females finish spawning before males. Irrespective of gender, vertical swimming activity was most pronounced during spawning, with descents towards the bottom dominating the movements. During spawning, males stayed significantly deeper than females. In conclusion, the present results suggest that initiation of spawning migration and duration of the spawning period differ between sexes, as does the level of activity during spawning events. Not all individuals followed the general pattern; a considerable number of individuals were found to spawn in shallow water in the Arkona Basin, and juvenile fish undertook the migration without spawning.
\end{abstract}

KEY WORDS: Baltic cod $\cdot$ Vertical migration $\cdot$ Reproduction $\cdot$ Spawning migration

\section{INTRODUCTION}

Many fish species undergo seasonal changes in distribution, as a result of migration between feeding, nursery and spawning areas. This is also the case with Baltic cod Gadus morhua. Most information available in previous studies describing the 'whereabouts' of Baltic cod has been obtained from trawl or hydroacoustic surveys (Tomkiewicz et al. 1998, Schaber et al. 2009, 2011). These studies are important in understanding the distributional characteristics of cod, however they do have the limitation of providing observations at a single point in time. The employment of archival tags, also known as data storage tags (DSTs), has proven a rather powerful tool for obtaining measurements of variables such as pressure (as a measure of depth) and temperature over extended time scales, records from which information about location and movement of individuals can be inferred (Neat et al. 2006, Shepard et al. 2006, Hobson et al. 2007, Svedäng et al. 2007). Essentially, movements of individuals are related to gradients of environmental parameters (Neuenfeldt et al. 2007, 2009) Despite some knowledge on movement patterns of cod during the spawning season, which indicate that fish move from shallow areas with low salinity into the deep, high-saline parts of the Bornholm Basin (Aro 1989, Tomkiewicz et al. 1998, Wieland et al. 2000, Neuenfeldt et al. 2007); individual timing and duration, and whether there are any genderspecific differences in these, are not known. Intuitively, reproductive phases may well correlate with 
the onset, as well as the termination, of the spawning migration. The maturity stage of the individual can be assessed histologically to infer its reproductive status at the time of recapture.

The Baltic Sea is a large, semi-enclosed estuary consisting of several basins. The eastern part of this area, including the Bornholm Basin, is characterised by a vertically stratified environment with a lowsalinity $(\sim 7 \mathrm{psu})$ surface layer (due to freshwater runoff from river discharge) extending to depths of 45 to $65 \mathrm{~m}$, where a permanent pycnocline separates the upper layer from the more saline (10 to $18 \mathrm{psu}$ ) bottom waters reaching down to a maximum depth of ca. 100 m (Matthäus \& Franck 1992, Schinke \& Matthäus 1998).

Absence of major inflows of high-saline, oxygenrich North Sea water results in low oxygen content below the halocline, and the bottom waters are almost permanently hypoxic (Conley et al. 2002). The Arkona Basin, just west of Bornholm, has a maximum depth of $53 \mathrm{~m}$, which is considerably shallower than the Bornholm Basin, with a maximum depth of $105 \mathrm{~m}$ (Leppäranta \& Myrberg 2009). The area is hydrographically dynamic but has higher salinity levels than the Bornholm Basin at comparable depths, irrespective of time of the year (Leppäranta \& Myrberg 2009). In these environments, Baltic cod Gadus morhua live and thrive, utilising more or less the entire Baltic Sea during the feeding season, though with particular preference for shallower coastal zones (Aro 1989 and references therein). The main spawning area of cod in the eastern Baltic Sea is the Bornholm Basin. From March onwards reproducing cod initiate migration towards the deep saline waters of this basin (Aro 1989, Righton et al. 2010, Schaber et al. 2011). Here, the prevailing salinity ( $>11 \mathrm{psu}$ ) and oxygen conditions $\left(>2 \mathrm{ml} \mathrm{l}^{-1}\right.$ ) allow for proper spermatozoa activation, neutral buoyancy of eggs in the water column and successful hatching (Westin \& Nissling 1991, Wieland et al. 1994, Vallin \& Nissling 2000), conditions which are unique to this location.

Due to unique oxygen and salinity prevailing within the eastern Baltic, this area provides an excellent setting for identifying the location and movement of DST-tagged fish. Consequently, we attempted, as a novel approach, to couple rather 'simple' DSTderived measurements of the surrounding environment with information on the reproductive state of individual fish. Such attempts may help us in answering the more ambitious question of 'where fish are and why'. By combining histological analysis of reproductive organs - to accurately determine the reproductive phase of individually tagged Baltic cod- with the migratory patterns derived from DSTs, we aimed to describe sex-specific variations in, and details of, spawning migration initiation and duration, as well as vertical behaviour at the spawning site.

\section{MATERIALS AND METHODS}

\section{Tagging and recapture of fish}

During April and May 2004 to 2006, 2 mo before the main spawning season, 382 Baltic cod in the eastern Baltic Sea were externally tagged with DSTs. Individuals $>40 \mathrm{~cm}$ total length were selected to insure there was a high chance they were sexually mature and could carry the tag without affecting their natural behaviour and condition (Righton et al. 2006). The size range for tagged cod at release was 44 to $95 \mathrm{~cm}$. The cod were caught by longline at a bottom depth of 30 to $40 \mathrm{~m}$ from a chartered fishing vessel at different stations. To avoid damage of the swim bladder the captured fish were raised slowly to the surface over $15 \mathrm{~min}$. Individual cod were anaesthetised using MS-222 (Sandoz; dosage 1:20000), and total length $(\mathrm{cm})$ and weight $(\mathrm{g})$ were measured, thereafter DSTs were fixed behind the first dorsal fin in the dorsal musculature as described by Neuenfeldt et al. (2007). The procedure of tagging was completed within $2 \mathrm{~min}$. Then, the cod were gently released from the stationary vessel, all at the same location (Fig. 1). Commercial and recreational fishermen returned the cod after recapture for a reward. Recapture sites where latitude and longitude were reported are shown in Fig. 1. The remaining fish were all recaptured 'east of Nexø'. The cod were dead when returned and stored at $-18^{\circ} \mathrm{C}$ for up to ca. 4 yr.

\section{DST data}

The DSTs (DST-CTD, Star-Oddi) were programmed to record ambient pressure $\left(P_{\mathrm{i}}\right.$, resolution $=0.03 \mathrm{bar}$, which was converted into depth $(\mathrm{m}))$, temperature (resolution $=0.032^{\circ} \mathrm{C}$ ) and conductivity (resolution = $0.02 \mathrm{psu}$ ) every $15 \mathrm{~min}$ in 2004 and every $12 \mathrm{~min}$ in 2005 and 2006. A slight error emerges when converting pressure into depth due to a vertical density gradient $(<3 \%$ in the study area; S. Neuenfeldt pers. comm.) caused by waves and changes in atmospheric pressure. Data from the first $7 \mathrm{~d}$ post-tagging were discarded to avoid effects of the tagging procedure on the behaviour of the fish (van der Kooij et al. 


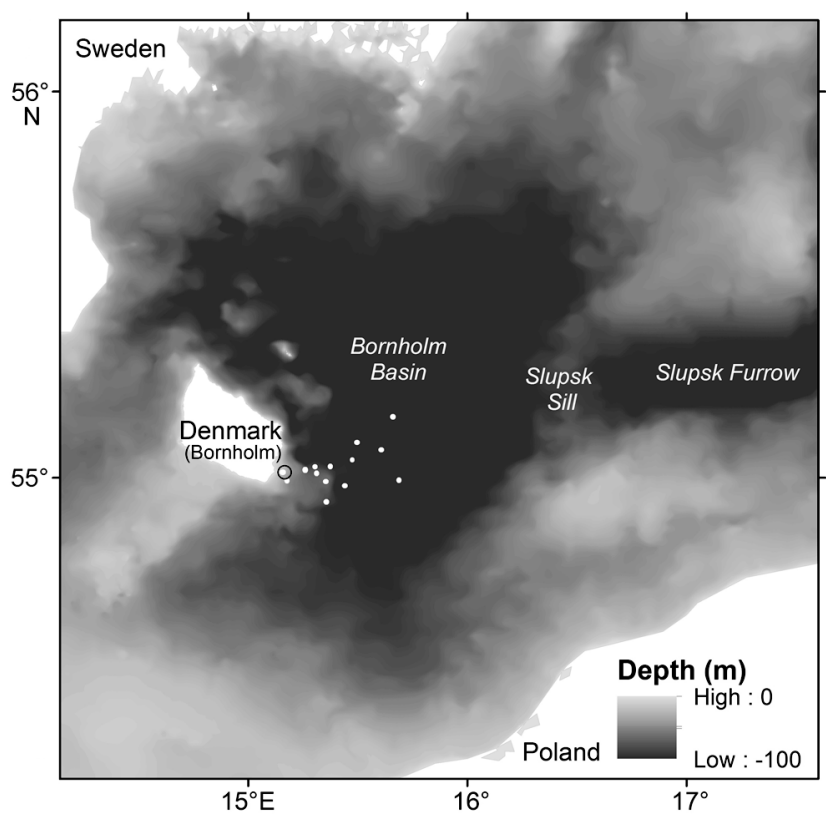

Fig. 1. Gadus morhua. Map of the Baltic Sea with the release site (open circle) and recapture sites (white dots) of Baltic cod equipped with data storage tags

2007). DST data from a total of 184 cod formed the basis of the selection of individuals for detailed analyses.

\section{Histology of recaptured fish}

After recapture and storage at $-18^{\circ} \mathrm{C}$ the cod were thawed and dissected and different organs such as liver and gonads were stored separately at $-18^{\circ} \mathrm{C}$ for up to 4 yr. Ovaries and testes from 184 re-captured cod were partly thawed, and tissue from each gonad was fixed in formalin (4\%) buffered with $\mathrm{NaH}_{2} \mathrm{PO}_{4}$. $\mathrm{H}_{2} \mathrm{O}$ and $\mathrm{NaHPO}_{4} \cdot 2 \mathrm{H}_{2} \mathrm{O}$ for later histological examinations. In the laboratory, the samples were embedded in paraffin; three $5 \mu \mathrm{m}$ sections at 25 to $50 \mu \mathrm{m}$ distance were stained with Ehrlich's haematoxylin and eosin for qualitative determination of reproductive status of the individuals. Freezing of gonads damages the structure of the cells, and the formation of ice crystals can break some of the membranes. However, Nielsen (2009) established reliable morphological criteria for assessing the reproductive phases of frozen gonads by comparing histological processed frozen and formalin-preserved gonad samples from individual female and male cod. This resulted in a manual aligning histological samples from frozen and formalin-preserved gonads. Six different reproductive phases were distinguished corresponding to
1 or more maturity stages (Tomkiewicz et al. 2003), while maturity stages within phases could not be separated using frozen gonads (Table 1). These 6 different reproductive phases were used to identify the reproductive status of each individual.

Histological examinations also provided information on previous reproductive activity in the form of remains of spawning products such as degenerating spermatozoa in the sperm ducts, atretic oocytes and encapsulated residual eggs, as well as gonad wall thickness.

\section{Sample selection for detailed analyses}

Of the 184 recaptured fish, 21 females and 19 males were selected for the study based on the following criteria: (1) sufficient days at liberty to cover the entire spawning period, (2) the number of females and males in the analysis are close to 50:50, (3) hydrographic conditions are approximately equal between years, and (4) coverage of reproductive phases 2 to 5, for both sexes (Table 1). Individual weight, length, sex and reproductive phase were determined.

\section{Vertical activity}

For each individual fish i 3 indices of vertical activity were calculated for each day $t$ based on occupied depth $P_{\mathrm{i}}$. Index 1 is mean depth $\bar{P}(t)_{i}$ as a proxy for mean depth range occupied:

$$
\bar{P}(t)_{i}=\sum_{\mathrm{t}=1}^{\mathrm{n}} P(t)_{i} \cdot \mathrm{n}-1
$$

Table 1. Gadus morhua. Reproductive phases (numbers and description) verified for frozen samples in Nielsen (2009) corresponding to maturity stages and reproductive phases described by Tomkiewicz et al. (2003)

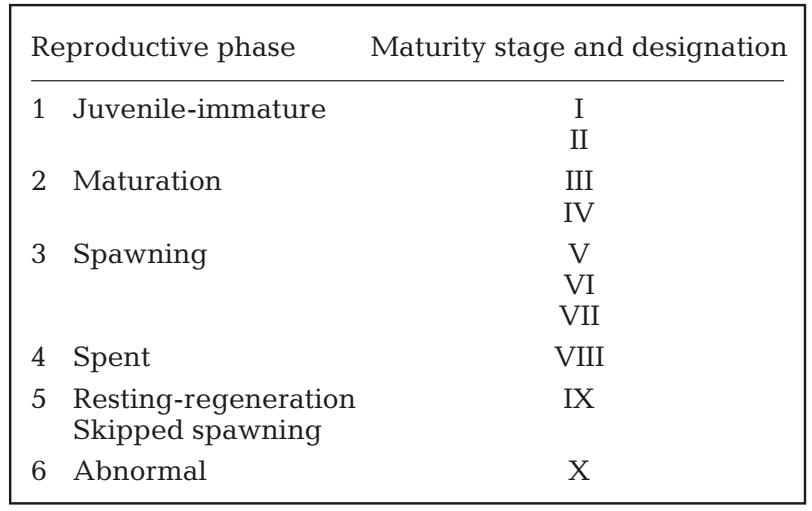


where $P(t)_{i}$ is the depth experienced by individual $i$ at any day $t$ of DST data and $\mathrm{n}$ is the number of observations that day.

Index 2 is absolute depth difference $\Delta \bar{P}(t)$ as a proxy of maximum extent of daily vertical migration:

$$
\Delta \bar{P}(t)=\max \left[P(t)_{i}\right]-\min \left[P(t)_{i}\right]
$$

where $\max \left[P(t)_{i}\right]$ is the maximum depth recorded on a given day and $\min \left[P(t)_{i}\right]$ is the shallowest depth.

Finally, Index 3 is $\gamma$, an expression of symmetry in vertical movements:

$$
\gamma=\bar{P}(t)_{i}-\frac{\max \cdot\left[P(t)_{i}\right]+\min \cdot\left[P(t)_{i}\right]}{2}
$$

Negative values of $\gamma$ indicate vertical movements dominated by ascents in the water column followed by corresponding descents, whereas positive values correspond to descents towards the sea bottom followed by ascents.

\section{Definitions of behavioural periods}

Based on the depth and salinity records from the DST time series, the 3 behavioural periods 'prespawning,' 'spawning' and 'post-spawning' were defined for each individual fish (Fig. 2). The onset of migration towards the spawning area $\left(t_{\text {start }}\right)$ was determined as the time at which a rapid increase in depth and/or salinity occurred crossing the $50 \mathrm{~m}$ isobath, followed by a prolonged period at these conditions, according to the procedure described by Hüssy et al. (2009). The period below the $50 \mathrm{~m}$ isobath was defined as the 'spawning' period. 'Pre-spawning' was defined as the period from release until onset of seasonal migration towards saline waters. The beginning of the 'post-spawning' period was defined as the day when the fish moved back into water shallower than 50 m (Fig. 2).

Behavioural characteristics of the 3 periods were analysed by aligning the time axis for each individual with $t_{\text {start. This }}$ procedure facilitated visual interpretation and comparison of vertical behaviour in relation to sex, different migration periods and reproductive phases. The individuals were grouped by sex and reproductive phase to analyse differences in vertical activity between females/males in different phases. All values reported are means $( \pm \mathrm{SD})$ unless otherwise stated.

\section{Statistical analyses}

All statistical analyses were carried out in $\mathrm{R}$ v.2.12.2 (R Development Core Team 2009). Data were tested for normality and homogeneity of variances using a Shapiro-Wilk normality test and Ftests. As all data were normally distributed and with equal variance, they were compared using ANOVA. Comparisons of data from different behavioral periods within the same individuals were carried out using paired $t$-tests. Discrete data were compared using the Kruskal-Wallis rank sum test. An $\alpha$ of 0.05 was used as the level of significance.

\section{RESULTS}

All the results are based on analyses of the 40 selected individual Gadus morhua. Individuals recaptured during the 'pre-spawning' period were all immature or maturing (Reproductive Phases 1 and 2), while individuals caught during the 'spawning' period were either spawning (Phase 3) or had recently spawned (Phase 4). Individuals caught in the 'post-spawning' period were all spent or resting (Phases 4 and 5).

\section{Timing of spawning migration}

Male spawning migration began on the 157th day of the year $( \pm 19 \mathrm{~d})$ (corresponding to 6 June), which was earlier than for females starting on the 169th day of

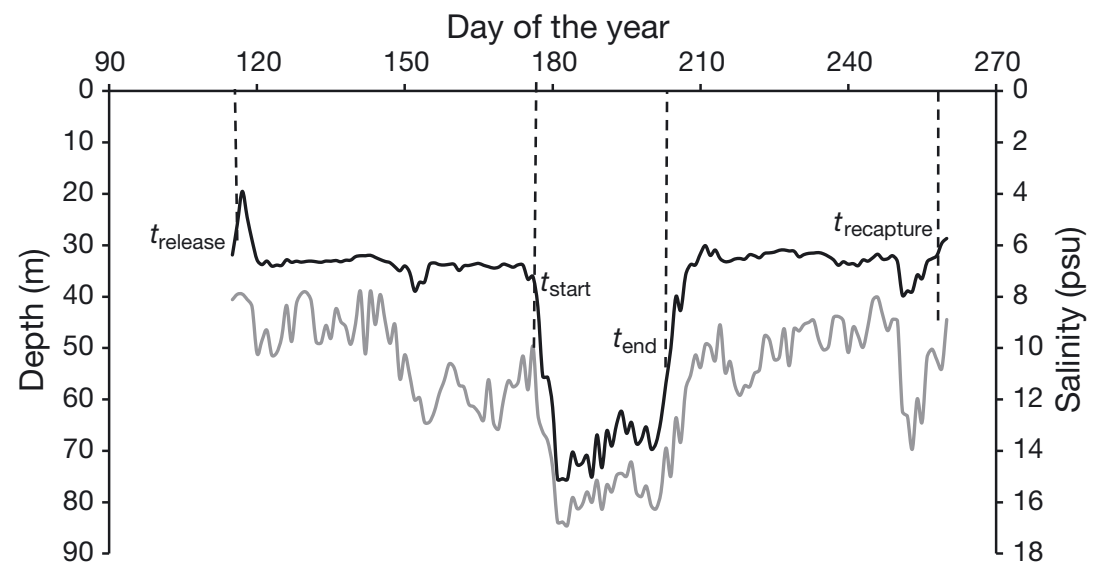

Fig. 2. Gadus morhua. Time series of depth (black line) and salinity (grey line) data for a tagged female cod (F13). Release after tagging $\left(t_{\text {release }}\right)$, onset of spawning migration $\left(t_{\text {start }}\right)$, end of spawning $\left(t_{\text {end }}\right)$ and recapture $\left(t_{\text {recapture }}\right)$ are illustrated on the profile. Pre-spawning is the period between $t_{\text {release }}$ and $t_{\text {start, }}$ spawning is the period between $t_{\text {start }}$ and $t_{\text {end, }}$ and post-spawning corresponds to the period between $t_{\text {end }}$ and $t_{\text {recapture }}$ 
the year $( \pm 21 \mathrm{~d}$ ) (corresponding to 18 June), albeit this difference was not statistically significant (KruskalWallis rank sum test, $\chi^{2}=2.942, \mathrm{df}=1, \mathrm{p}=0.08$ ) (Fig. 3c). Duration of the spawning migration and the accompanying daily increase in depth were similar between sexes. In general, the depth increased immediately after onset of migration and continued to do so for $11 \mathrm{~d}$. Subsequently, it stabilised at $60 \mathrm{~m}$ for both sexes, indicating arrival in the spawning area at the centre of the
Bornholm Basin (Fig. 1). The slope of the descent was almost linear for females $\left(r^{2}=0.814, p<0.05\right)$ and males $\left(r^{2}=0.862, p<0.05\right)$. During this period of migration, the mean depth increase was $1.7 \mathrm{~m} \mathrm{~d}^{-1}( \pm 2)$ for females and $1.6 \mathrm{~m} \mathrm{~d}^{-1}( \pm 2)$ for males (Fig. 3c,d). This means that the 2 sexes swim at the same speed towards the spawning area. The length of the females ranged from 43 to $96 \mathrm{~cm}$, with a tendency (however not significant) for larger females to initiate their
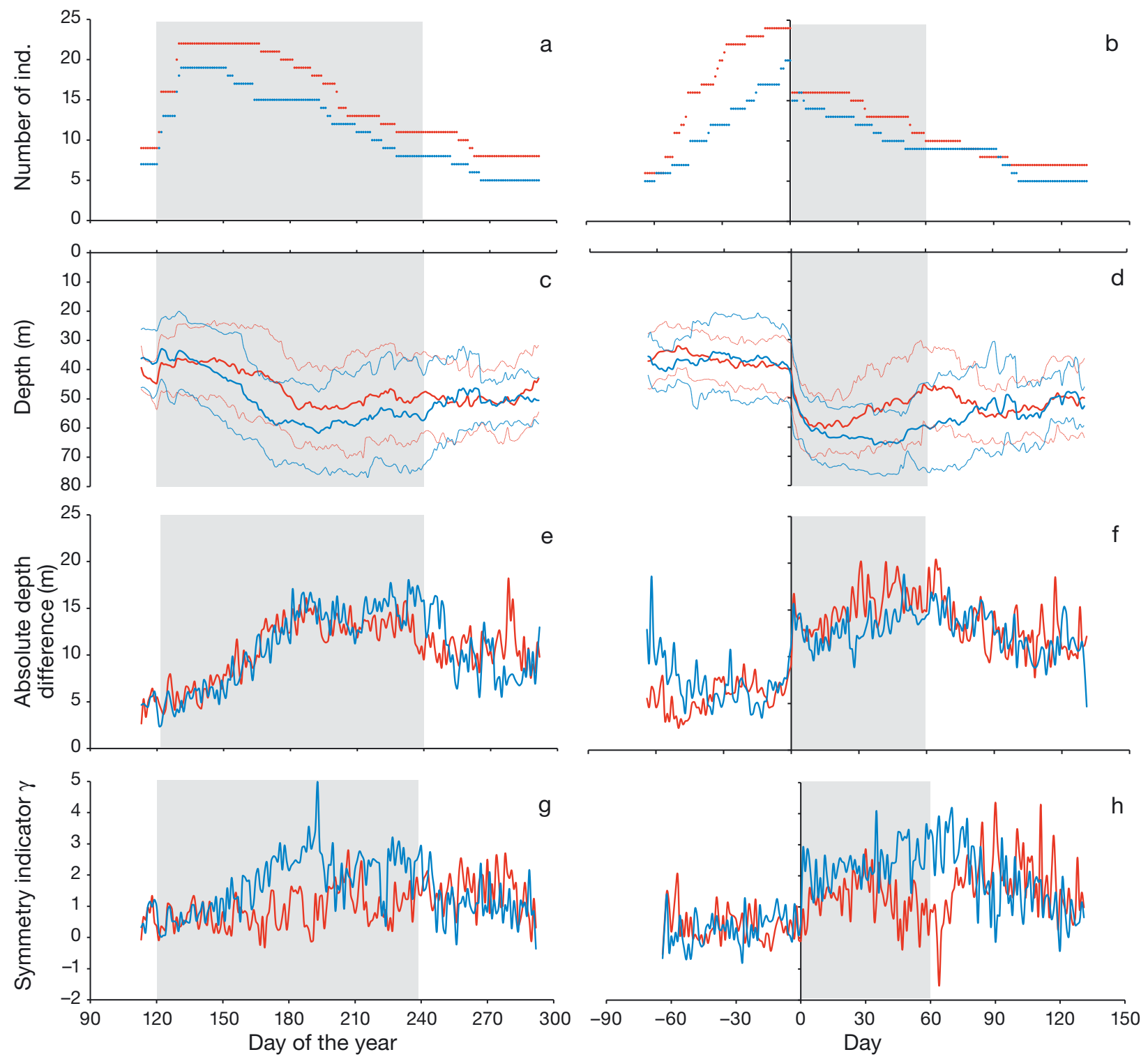

Fig. 3. Gadus morhua. The number of females (red) and males (blue) recaptured in relation to (a) day of the year and (b) days in relation to the onset of spawning. The vertical behaviour of 21 female and 19 male selected Baltic cod were analysed. Grey shading denotes the spawning season (a,c,e,g) May to August (MacKenzie et al. 1996, 2000, Vallin \& Nissling 2000) and spawning period/duration ( $b, d, f, h)$ of 4 to $8 \mathrm{wk}$ (Kjesbu 1989). The time scale in Panels $b, d, f$ and $h$ is corrected according to the individual determined day of onset of spawning migration, zero corresponding to the onset. Measures were only calculated on days where data from $\geq 5$ ind. per sex were available ( $a$ and b). The vertical behaviours of the 40 individual Baltic cod were analysed by 3 measures based on depth calculated on a daily basis: $(c, d)$ the mean daily depth $( \pm S D$, faded lines), $(e, f)$ the absolute depth difference during the day and $(g, h)$ daily symmetry indicator $\gamma$ of vertical movements. Negative values of $\gamma$ indicate vertical movements dominated by ascents up into the water column followed by corresponding descents. Positive values correspond to descents towards sea bottom, again followed by ascents 
spawning migration earlier than smaller ones $\left(t_{\text {start }}=\right.$ $134+0.60 \mathrm{SL}, \mathrm{r}^{2}=0.28, \mathrm{p}=0.07$ ). There was no correlation between male length and onset of migration $\left(t_{\text {start }}=206\right.$ to $\left.0.97 \mathrm{SL}, \mathrm{r}^{2}=0.07, \mathrm{p}=0.40\right)$, males ranging in size from 44 to $56 \mathrm{~cm}$.

\section{Duration of the spawning period}

The duration of the individual spawning period (defined as time spent below the $50 \mathrm{~m}$ isobath) did not differ significantly between sexes (female: $95 \mathrm{~d}$, range: 26 to $145 \mathrm{~d}$; male: $93 \mathrm{~d}$, range: 51 to $143 \mathrm{~d}$ ) (Kruskal-Wallis rank sum test, $\chi^{2}=0.03$, df $=1, \mathrm{p}=$ 0.86). However, the fact that all females recaptured $<50 \mathrm{~d}$ after onset of spawning migration were already spent suggests that females, in general, finish spawning before males, but may remain in the deep water for some time thereafter (Figs. 3c \& 4). This was supported by the difference in the distribution of reproductive phases between sexes of all 184 recaptured individuals (Fig. 4).

\section{Vertical migrations}

The depth occupation and activity patterns were analysed for each of the periods 'pre-spawning', 'spawning' and 'post-spawning' separately, as well as changes between subsequent periods. The results below are summarised in Table 2.

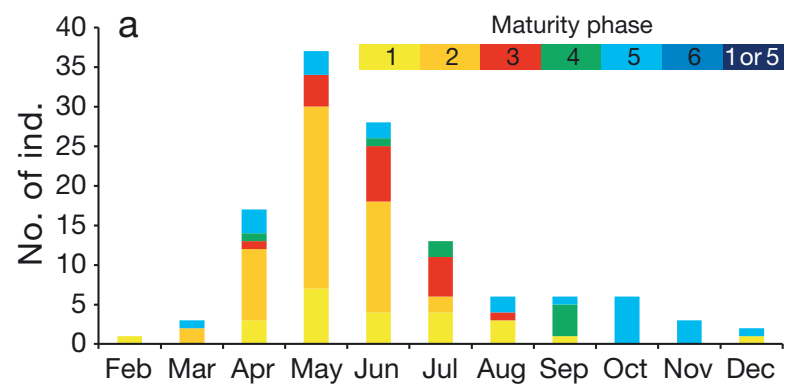

The 'pre-spawning' period was characterised by fish staying in shallow water with low activity for up to 2 mo prior to spawning migration (Figs. $3 \& 5$ ). During this period no significant differences were observed between sexes in depth occupation or activity.

During 'spawning' both sexes occupied deeper water than during the 'pre-spawning' period. For females, depth occupation increased from 37 to $61 \mathrm{~m}$ (paired $t$-test: $t=-6.936, \mathrm{df}=11, \mathrm{p}<0.001)$, for males depth increased from 35 to $66 \mathrm{~m}$ (paired $t$-test: $t=$ -10.556 , df $=12, p<0.001$ ), with males staying significantly deeper than females. The activity level of both sexes increased significantly from 'pre-spawning' to 'spawning' (paired $t$-test: $t_{\text {female }}=-3.980, \mathrm{df}_{\text {female }}=11$, $\left.\mathrm{p}_{\text {female }}<0.01 ; t_{\text {male }}=-4.379, \mathrm{df}_{\text {male }}=12, \mathrm{p}_{\text {male }}<0.001\right)$, but without differences between the sexes (both females and males: $14 \pm 4 \mathrm{~m} \mathrm{~d}^{-1}$ ).

From 'spawning' to 'post-spawning', a significant change in depth preference occurred in both sexes (paired $t$-test: $t_{\text {female }}=3.285, \mathrm{df}_{\text {female }}=5, \mathrm{p}_{\text {female }}<0.05$; $\left.t_{\text {male }}=5.008, \mathrm{df}_{\text {male }}=7, \mathrm{p}_{\text {male }}<0.01\right)$. Male activity did not decrease significantly following spawning (paired $t$-test: $t=1.646$, df $=7, \mathrm{p}=0.14$ ), but decreased significantly in females (paired $t$-test: $t=3.998$, df $=5$, $\mathrm{p}<0.05$ ) (Fig. 3d,f). Neither depth occupation nor activity differed between sexes (Table 2).

The vertical movement symmetry indicator $\gamma$ was positive for both sexes, which indicates that individuals were staying high in the water column while regularly referring to the bottom. Throughout the 'pre-

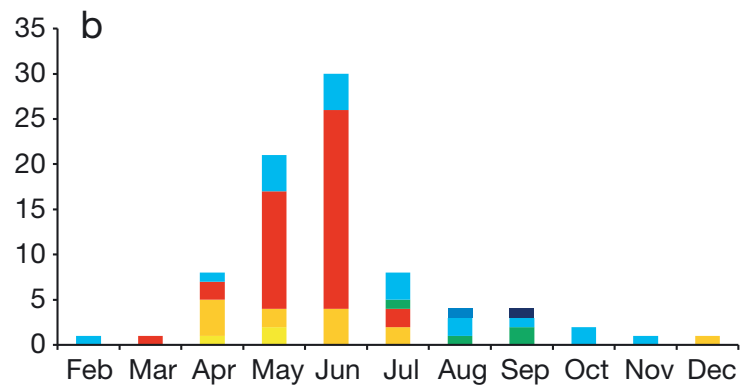

Fig. 4. Gadus morhua. Distribution of the number of individuals by maturity phase, for all recaptured (a) female and (b) male cod according to the month of recapture

Table 2. Gadus morhua. Summary of depth occupation and activity patterns for each behavioural period and sex, including ANOVA results of between-sex comparisons

\begin{tabular}{|c|c|c|c|c|c|c|c|c|c|c|}
\hline & \multicolumn{5}{|c|}{ Depth (m) } & \multicolumn{5}{|c|}{-Activity ( $\left.\mathrm{m} \mathrm{d}^{-1}\right)$} \\
\hline & Female & Male & $F$ & df & $\mathrm{p}$ & Female & Male & $F$ & df & $\mathrm{p}$ \\
\hline Pre-spawning & $37 \pm 8$ & $35 \pm 0.9$ & 0.731 & 1,38 & 0.39 & $8 \pm 6$ & $7 \pm 0.5$ & 0.435 & 1,38 & 0.53 \\
\hline Spawning & $61 \pm 4$ & $66 \pm 5$ & 4.436 & 1,21 & 0.048 & $14 \pm 4$ & $14 \pm 4$ & 0.161 & 1,21 & 0.69 \\
\hline Post-spawning & $43 \pm 10$ & $43 \pm 6$ & 0.00027 & 1,12 & 0.99 & $10 \pm 4$ & $11 \pm 0.5$ & 0.374 & 1,12 & 0.55 \\
\hline
\end{tabular}



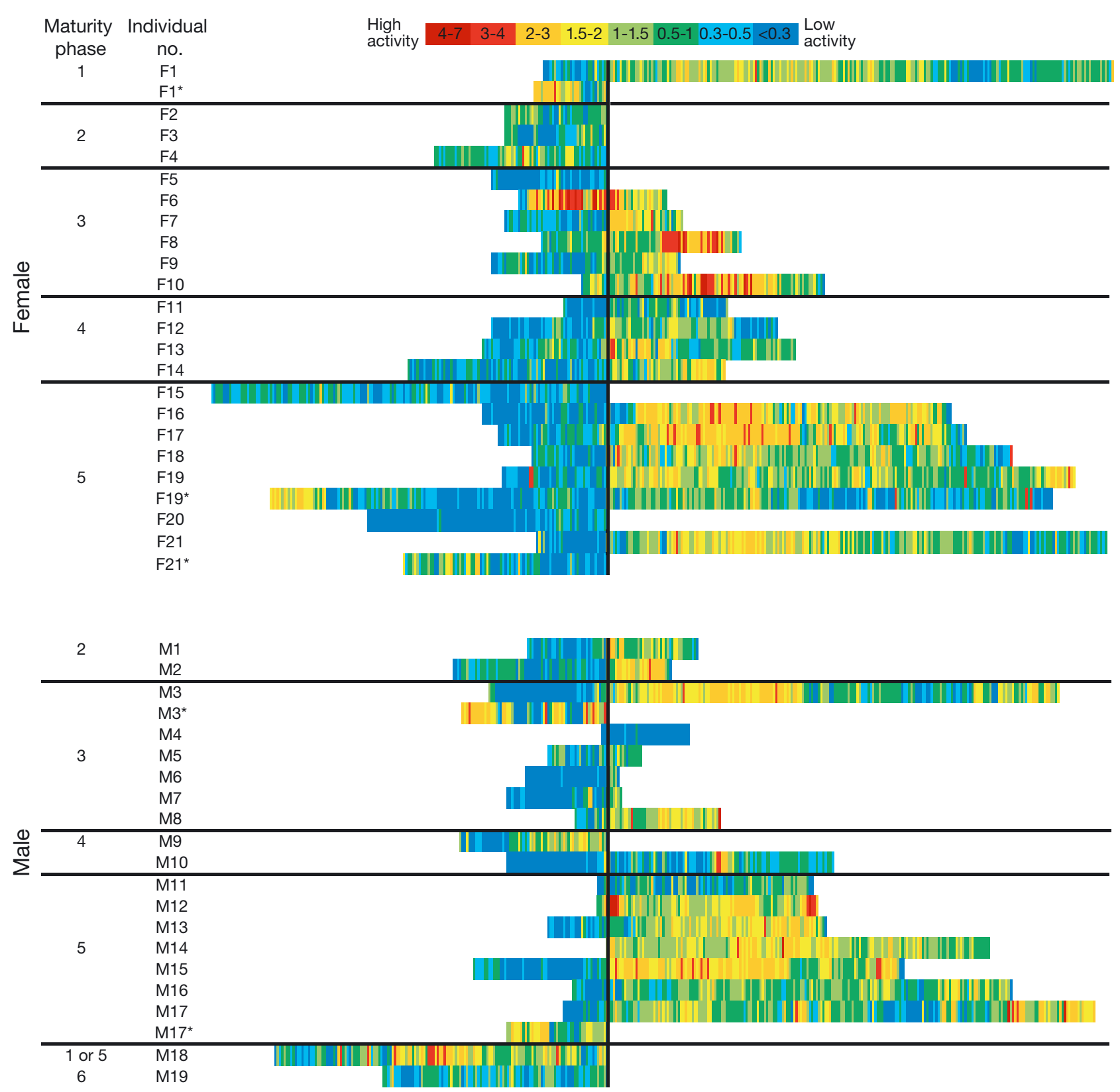

Fig. 5. Gadus morhua. Vertical activity as absolute depth difference per day for 21 female and 19 male Baltic cod. The individuals are sorted by maturity phase and recapture day. The horizontal black lines separate the maturity phases, and the vertical black line denotes the onset of spawning migration. The time scale is corrected after day of onset of spawning migration; thus, Day 0 corresponds to the day of onset - relative time. Note that 3 females (F1, F19 and F21) and 2 males (M3 and M17) were at liberty for $>1 \mathrm{yr}$; these individuals are marked with asterisks when the second year is initiated. Two individuals (F21* and $\mathrm{M}^{*} 7^{*}$ ) were characterised as skip spawners. No signs of recent spawning were found in F20, but, as the recapture date was

15 August, it was difficult to assess whether it was in the resting-regeneration phase or skipped spawning

spawning' period, $\gamma$ was zero (females and males: $0 \pm$ 0.2 ), indicating that vertical movements were equally distributed between ascents and descents (Fig. 3h). Hence, females were not associated with the seabed and continued to search the water column. Males tended to undertake more descents towards the seabed during the spawning period than did females, whose activity could be described by alternations between ascents and descents (Fig. 3h). This difference between the sexes in their vertical activity was especially pronounced throughout the second month, after the onset of spawning migration (Fig. 3h). 


\section{Repetitiveness of behaviour}

For 3 fish (all females) DST information for 2 consecutive years (including 2 potential spawning seasons) were obtained. One of these fish (F19) undertook a spawning migration in both years, with the onset date changing only by $9 \mathrm{~d}$ between years (Fig. 5). The 2 other females (F21* and M17*) either skipped spawning or delayed their spawning period compared to their first year at liberty. Histological examination verified that these individuals had spawned previously, which fits well with the observed onset of migration during the first year at liberty and no signs of re-maturation (Fig. 5).

\section{Extraordinary behaviour patterns}

Among the 40 individuals in the detailed analysis, 6 females and 5 males showed behavioural patterns that did not conform to the general pattern. Three females (F8, F17 and F21) and 3 males (M4, M5 and M11) spawned in shallow waters with salinity $>11$ psu. This combination of conditions does not occur in the Bornholm Basin, but it does in the Arkona Sea, suggesting that these cod were spawning here. Additionally, 2 females (F5 and F15) and 2 males (M3 and M9) did not migrate towards deeper and more saline waters (Fig. 5) where spawning normally occurs, but histological examinations of their gonads revealed fresh residual eggs or sperm remains, indicating ongoing or recent spawning. Finally, 1 female (F1), characterised as immature, as no signs of spawning were visible, migrated towards more saline water (>11 psu) during the spawning season (Fig. 5).

\section{DISCUSSION}

Whereas traditional survey-based studies observe temporal and spatial distribution patterns at the population level, and only as snapshots in time, DSTs allow tracking of an individual fish's behaviour with a very high temporal resolution. By combining information derived from DSTs with histology of reproductive organs, the present study provides new gender-specific details on the spawning migration of Baltic cod, more specifically the 'where about' and behaviour of individuals in relation to their reproductive phase. To our knowledge, this is a novel approach and the first description of such. In the following, the 'previous understanding' of Baltic cod spawning migrations and behavioural patterns is discussed in relation to the results of this study.

\section{General behaviour}

Several previous studies have reported that in the months prior to the spawning season, maturing Baltic cod are mainly distributed in shallow waters on the edge of the Bornholm Basin (Aro 1989, Bagge et al. 1994, Tomkiewicz \& Köster 1999). This study confirmed that during maturation stages cod preferred shallow water and did not undertake substantial vertical migrations during this period. Further, it is well known that during summer months, spawning cod aggregate (and hence occur in great abundance) in the deep part of Bornholm Basin (Tomkiewicz et al. 1998, Schaber et al. 2009, 2011). This was likewise confirmed by the present data as all but 2 individuals with gonadal indications of spawning migrated towards deep and saline waters. The duration of migrations from feeding grounds towards the spawning area did not differ between sexes and was on average completed within $11 \mathrm{~d}$. This suggests that once an individual reaches a certain stage of the maturation cycle, it moves towards the spawning area without any significant detours. The preference for deep, saline water during spawning is characteristic of Baltic cod, as most other cod stocks live in more saline water; this indicates an evolutionary adaption to estuarine circulation in that area, with a permanent halocline reproductive success is optimised (Westin \& Nissling 1991, Wieland et al. 1994, Vallin \& Nissling 2000).

\section{Duration and timing of spawning migrations}

Previous studies suggest that the Baltic cod spawning season covers the period from March to November and normally peaks in July/August, but with considerable inter-annual variability (Tomkiewicz \& Köster 1999, Wieland et al. 2000, Bleil et al. 2009). Laboratory experiments suggest that the spawning season for individuals lasts between 4 to $8 \mathrm{wk}$ (Vallin \& Nissling 2000), the duration seemingly independent of fish size (Robichaud \& Rose 2003). In the present study most spawning specimens occurred during May and June, extending into July. In general, both females and males stayed in the spawning area for up to $3 \mathrm{mo}$, after which they migrated back towards shallower waters. However, all females caught within $50 \mathrm{~d}$ after the onset of spawning migration were already spent, which corresponds well with the duration of the spawning season observed in the laboratory (Vallin \& Nissling 2000). The same tendency was not apparent for males, which indicates 
that females may finish spawning before males, but stay in the spawning area for a period of time following spawning.

Previous studies of the timing of spawning migration, as well as the duration of the spawning season, have indicated prolonged male residence in the spawning areas of Baltic cod (Bleil \& Oeberst 1997, Tomkiewicz \& Köster 1999), which seems to be a general feature of cod reproduction (Morgan \& Trippel 1996, Lawson \& Rose 2000). The difference in duration of the spawning period causes a higher catchability of males than of females if fishing is performed in the spawning areas (Morgan \& Trippel 1996, Tomkiewicz \& Köster 1999, Lawson \& Rose 2000). The same trends were observed in the present study, but the differences were not significant. This may be due to the relatively small sample size in the present study and the fact that the samples do not represent the entire size range of the spawning population. Also, the definition of when the individual fish's migration starts and ends is based on subjective criteria.

Several studies suggest that the timing of Baltic cod spawning migrations depend on fish size, whereby large and old fish start to spawn earlier than do small and young individuals (Bleil \& Oeberst 1997, Tomkiewicz \& Köster 1999), a pattern that also applies to other cod stocks (Kjesbu et al. 1996, Thorsteinsson \& Marteinsdottir 1998, Lawson \& Rose 2000). The present results on female cod support this, as a positive yet non-significant correlation between female length and date of onset of spawning migration suggests that larger female spawners may in fact start their migrations earlier than smaller ones. In the present study, the male length range was narrow and differences could not be detected.

\section{Vertical swimming activity}

During the spawning period, Baltic cod males resided at significantly greater depth than did females. Sex-specific vertical distribution in the water column during the spawning season also occurs in other cod stocks, but with males occupying shallower water (Morgan \& Trippel 1996, Windle \& Rose 2007). The reason for this difference between the Baltic and other cod stocks remains unclear. It may however be related to the rather unique hydrographical conditions prevailing in the Bornholm Basin, with concurrent strong halo- and thermoclines during the summer months (Neuenfeldt \& Beyer 2003), which likely influence where the individual fish positions itself in the water column.
Increased vertical activity also seems a general feature of the mating behaviour (Windle \& Rose 2007). Cod in the present study exhibited considerably higher vertical swimming activity when in the spawning areas compared to prior to spawning. Activity levels were similar between sexes, whereas females alternated between ascents and descents, male movements were dominated by descents during spawning. These swimming patterns suggest complex mating behaviour, similar to that previously observed in captive cod, with complicated mating rituals including female initiation and termination of the ritual by vertical movements followed by male circling of the female (Hutchings et al. 1999).

\section{Extraordinary migration patterns}

A few cod in the present study did not comply with the general pattern, but instead spawned in shallow, high-saline water. The shallow water west of Bornholm is more saline than that east of the island. This suggests westward migration into the Arkona Basin instead of into the deep, high-saline waters at the depths of the Bornholm Basin. Such migration patterns have been evidenced before (e.g. Bleil et al. 2009). Also, spawning in shallow water with low salinity was observed in this study, indicating that these individuals apparently failed to migrate to areas with environmental conditions allowing successful reproduction. A proportion of the cod appeared to skip spawning, i.e. Phase 5 (Rideout et al. 2005, Rideout \& Tomkiewicz 2011). Assuming that the tagged population is representative of the entire eastern Baltic cod stock, then approximately $10 \%$ of a mature cohort skips reproduction. Furthermore, one juvenile fish migrated into the Bornholm Basin, but did not spawn. This suggests that some juveniles follow the adults on their migrations, possibly as a learning-by-doing process, as previously observed in Newfoundland (Lawson \& Rose 2000).

Where traditional survey-based studies observe temporal and spatial distributions only as snapshots through time, DSTs allow the tracking of an individual fish's timing. This study has demonstrated the power of combining methodologies; in part by confirming presumed knowledge, but even more so by documenting hitherto unknown behaviour such as the migration of a juvenile fish or the fact that a considerable proportion of the stock may spawn outside the presumed spawning area. 
Acknowledgements. This research was funded by the EU project CODYSSEY (QLRT-2001-00813). We gratefully acknowledge the help of skipper C. Holm and the crew and scientific staff onboard the commercial vessel 'Britta' for the tagging of fish. This study would not have been possible without the help of fishermen operating within the Baltic Sea, who returned tags and fish data to us. We also thank K. Geitner for providing the GIS map and I. Hornum for her assistance with histological analyses.

\section{LITERATURE CITED}

Aro E (1989) A review of fish migration patterns in the Baltic. Rapp P-V Reùn Cons Int Explor Mer 190:72-96

Bagge O, Thurow F, Steffensen E, Bay J (1994) The Baltic cod. Dana 10:1-28

Bleil M, Oeberst R (1997) The timing of the reproduction of cod (Gadus morhua morhua) in the western Baltic and adjacent areas. ICES Comm Meet 1997/CC:02

Bleil M, Oeberst R, Urrutia P (2009) Seasonal maturity development of Baltic cod in different spawning areas: importance of the Arkona Sea for the summer spawning stock. J Appl Ichthyology 25:10-17

Conley DJ, Humborg C, Rahm L, Savchuk OP, Wulff F (2002) Hypoxia in the Baltic Sea and basin-scale changes in the phosporus biogeochemistry. Environ Sci Technol 36:5315-5320

Hobson VJ, Righton D, Metcalfe JD, Hays GC (2007) Vertical movements of North Sea cod. Mar Ecol Prog Ser 347: 101-110

Hüssy K, Nielsen B, Mosegaard H, Clausen LW (2009) Using data storage tags to link otolith macrostructure in Baltic cod Gadus morhua with environmental conditions. Mar Ecol Prog Ser 378:161-170

Hutchings JA, Bishop TD, McGregor-Shaw CR (1999) Spawning behaviour of Atlantic cod, Gadus morhua: evidence of mate competition and mate choice in a broadcast spawner. Can J Fish Aquat Sci 56:97-104

Kjesbu OS (1989) The spawning activity of cod, Gadus morhua L. J Fish Biol 34:195-206

Kjesbu OS, Solemdal P, Bratland P, Fonn M (1996) Variation in annual egg production in individual captive Atlantic cod (Gadus morhua). Can J Fish Aquat Sci 53:610-620

> Lawson GL, Rose GA (2000) Small-scale spatial and temporal patterns in spawning of Atlantic cod (Gadus morhua) in coastal Newfoundland waters. Can J Fish Aquat Sci 57:1011-1024

Leppäranta M, Myrberg K (2009) Physical oceanography of the Baltic Sea. Springer Praxis, Chichester

MacKenzie B, John MS, Wieland K (1996) Eastern Baltic cod: perspectives from existing data on processes affecting growth and survival of eggs and larvae. Mar Ecol Prog Ser 134:265-281

- MacKenzie BR, Hinrichsen HH, Plikshs M, Wieland K, Zezera AS (2000) Quantifying environmental heterogeneity: habitat size necessary for successful development of cod Gadus morhua eggs in the Baltic Sea. Mar Ecol Prog Ser 193:143-156

Matthäus W, Franck H (1992) Characteristics of major Baltic inflows - a statistical analysis. Cont Shelf Res 12: 1375-1400

> Morgan MJ, Trippel EA (1996) Skewed sex ratios in spawning shoals of Atlantic cod (Gadus morhua). ICES J Mar Sci 53:820-826
Neat FC, Wright PJ, Zuur AF, Gibb IM and others (2006) Residency and depth movements of a coastal group of Atlantic cod (Gadus morhua L.). Mar Biol 148:643-654

Neuenfeldt S, Beyer JE (2003) Oxygen and salinity characteristics of predator--prey distributional overlaps shown by predatory Baltic cod during spawning. J Fish Biol 62: 168-183

> Neuenfeldt S, Hinrichsen HH, Nielsen A, Andersen KH (2007) Reconstructing migrations of individual cod (Gadus morhua L.) in the Baltic Sea by using electronic data storage tags. Fish Oceanogr 16:526-535

> Neuenfeldt S, Andersen K, Hinrichsen HH (2009) Some Atlantic cod Gadus morhua in the Baltic Sea visit hypoxic water briefly but often. J Fish Biol 75:290-294

Nielsen B (2009) Differences in individual behaviour of Baltic cod (Gadus morhua) in relation to sex, reproductive state and season. Master thesis, Technical University of Denmark, Copenhagen (Cwisno: 39610)

R Development Core Team (2009) R: a language and environment for statistical computing. R Foundation for Statistical Computing, Vienna

Rideout R, Tomkiewicz J (2011) Skipped spawning in fishes: more common than you might think. Mar Coast Fish 3: 176-189

> Rideout RM, Rose GA, Burton MPM (2005) Skipped spawning in female iteroparous fishes. Fish Fish 6:50-72

Righton D, Kjesbu OS, Metcalfe J (2006) A field and experimental evaluation of the effect of data storage tags on the growth of cod. J Fish Biol 68:385-400

Righton DA, Andersen KH, Neat F, Thorsteinsson V and others (2010) Thermal niche of Atlantic cod Gadus morhua: limits, tolerance and optima. Mar Ecol Prog Ser 420:1-13

Robichaud D, Rose GA (2004) Migratory behaviour and range in Atlantic cod: inference from a century of tagging. Fish Fish 5:185-214

Schaber M, Hinrichsen HH, Neuenfeldt S, Voss R (2009) Hydroacoustic resolution of small-scale vertical distribution in Baltic cod Gadus morhua-habitat choice and limits during spawning. Mar Ecol Prog Ser 377:239-253

Schaber M, Hinrichsen HH, Gröger JR (2011) Seasonal changes in vertical distribution patterns of cod (Gadus morhua) in the Bornholm Basin, central Baltic Sea. Fish Oceanogr 21:33-43

Schinke H, Matthäus W (1998) On the causes of major Baltic inflows - an analysis of long time series. Cont Shelf Res 18:67-97

Shepard ELC, Ahmed MZ, Southall EJ, Witt MJ, Metcalfe JD, Sims DW (2006) Diel and tidal rhythms in diving behaviour of pelagic sharks identified by signal processing of archival tagging data. Mar Ecol Prog Ser 328:205-213

Svedäng H, Righton D, Jonsson P (2007) Migratory behaviour of Atlantic cod Gadus morhua: natal homing is the prime stock-separating mechanism. Mar Ecol Prog Ser 345:1-12

Thorsteinsson V, Marteinsdottir G (1998) Size specific time and duration of spawning of cod (Gadus morhua) in Icelandic waters. In: ICES theme session on fisheries assessment methods, ICES Comm Meet 1998/DD:5:18

Tomkiewicz J, Köster FW (1999) Maturation process and spawning time of cod in the Bornholm Basin of the Baltic Sea: preliminary results. ICES Comm Meet 1999/Y:25

Tomkiewicz J, Lehmann KM, St John MA (1998) Oceanographic influences on the distribution of Baltic cod, Gadus morhua, during spawning in the Bornholm Basin of the Baltic Sea. Fish Oceanogr 7:48-62 
Tomkiewicz J, Tybjerg L, Jespersen Å (2003) Micro- and macroscopic characters staging gonadal maturation of female Baltic cod (Gadus morhua L.). J Fish Biol 62: 253-275

Vallin L, Nissling A (2000) Maternal effects on egg size and egg buoyancy of Baltic cod, Gadus morhua: implications for stock structure effects on recruitment. Fish Res 49:21-37

van der Kooij J, Righton D, Strand E, Michalsen K and others (2007) Life under pressure: insights from electronic datastorage tags into cod swimbladder function. ICES J Mar Sci 64:1293-1301

Westin L, Nissling A (1991) Effects of salinity on spermato-

Editorial responsibility: Christine Paetzold,

Oldendorf/Luhe, Germany zoa motility, percentage of fertilized eggs and egg development of Baltic cod (Gadus morhua), and implications for cod stock fluctuations in the Baltic. Mar Biol 108:5-9

Wieland K, Waller U, Schnack D (1994) Development of Baltic cod eggs at different levels of temperature and oxygen content. Dana 10:163-177

Wieland K, Jarre-Teichmann A, Horbowa K (2000) Changes in the timing of spawning of Baltic cod: possible causes and implications for recruitment. ICES J Mar Sci 57: 452-464

Windle MJS, Rose GA (2007) Do cod form spawning leks? Evidence from a Newfoundland spawning ground. Mar Biol 150:671-680

Submitted: October 17, 2012; Accepted: February 22, 2013 Proofs received from author(s): April 19, 2013 